\title{
El problema del origen del conocimiento en los sistemas racionalistas.
}

\section{Introducción histórica.}

Como problema puro, como cuestión epistemológica primaria hacia la cual se halle orientada la especulación de los grandes pensadores, como momento inicial de una construcción sistemática, la cuestión del origen del conocimiento no ha aparecido en realidad sino muy contadas veces en la temática de las obras clásicas. En el último Capítulo de la Crítica de la Razón Pura, Kant divide a los filósofos en empiristas y noologistas, según consideren que el origen de los conocimientos racionales puros derivan de la experiencia o si ellos por el contrario tienen su fuente en la razón independientemente de la experiencia. A partir de entonces, el problema del origen del conocimiento, que en la exposición histórica de Kant tenía alcances muy limitados, ha sido planteada reiteradamente por los epígonos, por los recopiladores de las grandes obras y por los historiadores de la filosofía.

Sin embargo, y en virtud de las implicaciones mutuas de lo epistemológico con las cuestiones propias de las restantes disciplinas filosóficas -y en especial la ontologíacabe descubrir, subsumido por decirlo así en el transfondo 
de los sistemas, el problema histórico del origen del conocimiento. Este problema, como queda dicho, se ha planteadin por lo general tan sólo como una interrogación incluícla en estructuras conceptuales complejísimas, imbricada con nociones no epistemológicas (ontológicas, psicológricas o de otra índole). Aparece casi siempre únicamente como un clemento implícito en las determinaciones grenerales de una concepción del mundo. Es, ordinariamente nada más que un mormento en el desarrollo de un pensamiento sistemático, momento que, por lo mismo, se resuelve según los presupuestos generales sustentados de antemano. En la exposición de las diferentes soluciones of recidas al problema del origen del conocimiento, es necesario atender a las líneas generales de los sistemas, interpretarlas, para luego extraer de esa interpretación la versión del modo de pensar de los diferentes au1tores sobre ese tema intransparente.

En algunos casos, sin embargo, el problema del origen es planteado explícitamente; se revela como una realidad patente e inmediata en el edificio de los sistemas y aún como cimiento necesario.

Nos proponemos enseguida ofrece sumariamente las soluciones dadas al problema del origen del conocimiento. Debemos advertir sin embargo que, históricamente considerado, dicho problema es equívoco. En efecto, como lo vamos a comprobar inmediatamente, él se encuentra revestido de significaciones muy diversas a lo largo de la historia de la filosofía. El motivo de esta obnubilación en el planteanien. to del problema del origen del conocimiento debemos encontrarlo provisionalmente en la circunstancia de que él no ha sido formulado como una cuestión aporética, situada más acá del desenvolvimiento sistemático de las doctrinas.

Para los sistemas racionalistas, la cuestión del origen 
es ante todo un problema lógico. Ella atañe al valor del conocimiento, a su validez. El punto de partida es la afirmación de que el verdadero conocimiento es sólo el conocimiento válido. Supeditado al conocimiento auténtico, se halla la doxa, la i'érite de fait.. Ha de haber por tanto una condición que otorgue autenticidad y validez al verdadero conocimiento. Esta condición está dada por las notas de necesidad y universaliclad, notas que no pueden derivar de la experiencia sino únicamente de la función lógico-racional. Así pues, el origen es el momento lógico del conocimiento, la condición que implica la legitimidad de su derecho para ser considerado como verdaderamente tal. En los sistemas racionalistas, el origen del conocimiento es una función lógica.

En las concepciones empiristas, la cuestión reviste una fisonomía radicalmente disínil. La pregtunta no se halla orientada hacia la validez del conociniento, ella no se inserta en !a esfera de la Lógica. Antes bien, aquí se formula una inquisición de carácter psicológico y la noción del origen la encontramos enclavada en el orden temporal. No hay un conocimiento sino en tanto que "algo" es conocido Ese algo debe ser dado al sujeto cognoscente en un momento determinado de su experiencia consciente. El problema del origen se desarrolla para satisfacer la cuestión que inquiere de dónde saca sus contenidos el conocimiento, de dónde derivan las ideas elementales de la conciencia. El conocimiento se origina por la dación de un contenido al entendimiento del sujeto. El conocimiento tiene un punto de partida, un comienzo temporal. Es absolutamente indudable que todas las cosas del mundo de los objetos naturales y de la experiencia interna se ofrecen o pueden ofrecerse al sujeto; las primeras, como abigarrado conjunto de cualidades sensibles que luego se tranmutan en sensaciones e ideas. Así pues, en los sistemas empiristas del origen del conocimiento es una función psicológica. 
Aristóteles no considera la cuestión descle un punto de vista tan rigurosanente unilaieral. Las cosas nos of eecen imágenes representativas de las nismas, estructuras sensibles que circundan de tinieblas a las esencias, cuyas formats luminosas $y$ etermales se agazapan en la realidad percibida. El conocimiento se origina en una operación del entendimiento agente, que actualiza la luz de las ideas, extrayéndolas de stis vestiduras de sombra y promoviendo su tradición al entendiniento pasivo. En la teoría aristotélica, el conocimiento secumple a través de un proceso bipolar, cuyos dos extremos se encuentran en el sujeto y en el objeto simultaneamente. En realiclad, la doctrina aristotélica sobre el origen del conocimiento no es sino uno de los momentos de su doctrina metafísica. El origen del conocimiento es para Aristóteles una función metafísica que se cumple en virtud de la peculiar organización del mundo natural y ce la estructura espiritual del sujeto. Ambos se insertan en una misma realidad metafísica.

La doctrina apriorista considera las cosas descle un nuevo punto de vista que, formalmente, se vincula con la anterior. En el orden del tiempo, todos nuestros conocimientos comienzan "con" la experiencia. El mundo natural nos ofrece nada más que un confuso y ciego desconcierto de sensaciones. Sin embargo, hay algo anterior al momento histórico de la experiencia. Ese algo anterior no es de naturaleza psicológica, sino más bien lógica, trascenctental. Son las condiciones sin las cuales no sería posible la experiencia. En estas condiciones debemos encontrar el origen de nuestros conocimientos. El origen del conocimiento es pues en la doctrina kantiana una función apriorística y trascendental.

Como vemos, una ojeada sumaria a las soluciones dadius 
al problema del origen del conocimiento basta para conven1cernos de que él ha sido planteado de manera siempre diversal. El no apunta a una significación unívoca. Sea este el motivo que nos determine a examinar el problema no descle el punto de vista de la consideración histórica sino más bien con un criterio que indague por el núcleo de cuestiones que cstán implicadas en toda elaboración sistemática e intente el esclarecimiento de las nociones generales que irradian de su centro.

El origen como problema general.

En primer lugar, la noción de origen incluye una idea de temporalidad. La relación entre el origen y el ser originado está desplegada en el tiempo. Es incuestionable que el origen está antes que lo originado y es su antecedente. Esta comprobación es de la mayor importancia para el esclarecimiento del problema del origen aplicado al campo de lo epistemlógico. Esta relación de temporalidad entre el origen y lo originado puede ser deserita como una continuidad. Lo consecuente, en dicha relacion, continua sin interrupciones, sin saltos ni vacíos a lo antecedente, y es un nuevo aspecto en el proceso de desenvolvimiento de este último. En este senticlo, el origen está presente por decirlo así en la realidad originada.

El origen no debe ser identificado con la causa. La causa es un principio de relación que establece una vinculación necesaria entre seres irreductibles entre sí, que se hallan de antemano separados y que mantienen una indeclinable autonomía a lo largo de toda la relación causal. El calor es la causa de la dilatación de los cuerpos; el calor determina una modificación sobre un ser que le es eternamente extranjero. 
Una bola de billar choca contra otra $y$ este chofue es lat cat1sa de que en la seganda se opere una modificacion con la pmsición que ocupa en el espacio. La catusa, pues pronnere relaciones entre seres que, aun cuanelo pertenczoin a las sulismas esferas ontológicas, son, cono indizidnales, extraños entre si. Estas relaciones pueden ser descritats en general como relaciones modificatorias de tu estado anterior en $11 n$ ser que es heterogénco con respecto al antecedente causal. Desde luego, también pueden suscitarse relaciones de catusa a efecto dentro de un mismo y único ser, si este ser organizat en su ámbito interior, en la unixlad de su dintorno, realidacles de naturaleza dispar. Una emoción puede ser la causa de ciertas modificaciones en el orgatmisno fisico del hombre. Pero la enoción como tal es una realidad rue no puede ser incluidal dentro de otral que ostente notas materiales.

El origen, por el contrario, no establece relaciones entre realidades heterogéncas. La flor halla su origen en la semilla; el río deriva de la fuente; los seres originados pueden ser considerados siempre cotno descnvolvimientos de los gérmenes potenciales contenidos en los seres orisinarios. I a semilla y la flor constituyen dos monentos de tuna misma realidad, dos faces en el proceso de desenvolviniento de un único ser. Por otra parte, si bien la calusa promtieve relaciones necesarias, el origen conticne unicamente posibilidades, latencias que pueden o no devenir actualidades.

Finalmente, es lícito distinguir entre origen y fundamento. El fundamento es un principio racional. El fundamento es la instancia primera en el proceso de funclamentación de toda existencia, el principio inicial y general que comprende en sí todos los principios particulares del ser, del conocer y del obrar. Este ente primero, qtie incluye el principio del ser real y el principio de razón, es descrito por Heides- 
ger como "el fundamento del fundanento o la razón de la razón". El origen es por el contrario un principio real y solamente un principio real.

Veamos ahora cuál es el residuo positivo que arroja al anterior exannen de la noción de origen. El origen es un tactor real, un principio real. En efecto, nada que carezca de realidad puede originar alguna realidad. La voluntad es un principio de esta naturaleza y constituye el origen del acto moral y del acto juridico. En segundo lugar, el origen es un factor de actividad. El origen es el comienzo de una mutación. En tercer lugar, las mutaciones que suscita el origen, como principio de actividad, no engendran trans-mutaciones en la naturaleza del ser originado. El ser originado es homogéneo con respecto a su origen, participa de su misma naturaleza y constituye tan sólo una faz en el proceso de la evolución del origen. Aquel es, con respecto a éste, tan sólo un idem esse. Por último, en el origen está implícita la idea de finalidad. En todo ser originario o en toda función originaria está latente una actividad que aspira al cumplimiento del teleos yue le es adecuado; tel desenvolvimiento de sus energías latentes, el desarrollo del seren sus nuevas facies.

El problema del origen en la teoria del conocimiento.

Inquirir por el origen del conocimiento no significa plantear el problema de cómo son ofrecidos a la conciencia los contenidos gnoseológicos ni, tampoco, cómo insurgen en aquélla las representaciones de los mismos. El problema del origen no debe entenderse psicológicamente; él no plantea la cuestión del comienso temporal de nuestros conocimientos.

En este problema, por otra parte, no está escondida ninguna iciea de causa. $\mathrm{Ni}$ los objetos reales del mundo exterior o interior ni los entes ideales "causan" el conocimiento. 
Toda causa supone un contacto entre el antecedente y el efecto. En la función cognoscitiva no hay ningin contacto entre sujeto y objeto, que son polos irrevocablemente separados de una relación. Las esferas del sujeto y del objeto son trascendentes entre si y en esta polarización orientada hacia reinos divergentes del ser, encontramos, como obsirva Nicolai Hartmann, la aporía general del conocimiento.

En el conocimiento se enfrentan un sujeto y un objeto. $¿$ Podemos encontrar el origen del conocimiento en alguno de los dos extremos de la relación epistemológica? No es posible hallar el origen del conocimiento en el sujeto; ninguna función espiritual del sujeto puede originar el conocimiento. Todo lo que en el sujeto está, por decirlo así, más acá de la relación cognoscitiva (v. g. la "razón") es intrascendente para el conocimiento y carece de significación para él. Es indudable que la nuda actividad del ser espiritual no podría originar por sí misma ningún conocimiento. En todo conocimiento se ofrece un contenido objetivo, que como tal reproduce los rasgos peculiares del objeto conocido.

Pero tampoco podemos buscar en el objeto el origen del conocimiento. El objeto es trascendentecon respecto al su.jeto y en la conciencia cognoscente esta trascendencia se mantiene incólume. El objeto conocido es sin duda objetivo pues es portador de las cualidades del objeto en cuanto tal; pero aquel no es ninguna derivación de éste ni constituye un momento de su desarrollo. Pero hay todavía más. Todo origen incluye la idea de actividad. Ahora bien. No hay ningún fundamento para admitir una actividad intencional de los objetos.

¿Podrá entonces encontrarse el origen del conocimiento en una actividad concurrente del sujeto y del objeto? Evidentemente no. Esta ocurrencia es en principio imposible. 
El objeto no puede desarrollar ninguna actividad. El sujeto, como actividad, no incorpora dentro de si el objeto, no lo "toca". Y. por otra parte, sujeto y objeto pertenecen a esferas heterogéneas del ser. No hay origen que pueda originar una realidad que no le sea homogénea.

Tampoco podemos encontrar el origen del conocimiento en la relación cognoscitiva misma como tal. Ella es "actual, metalógica, metafísica". Su estructura no es anímica ni tampoco iđeal; ella tiene una legalidad peculiar de esencia incomparable (Hartmann). Esta relación se constituye inmediatamente como una unidad cerrada; se ofrece como una integridad inmediata, en la que no cabe descubrir antecedentes ni tampoco momentos evolutivos. Racionalmente, no es posible, pues, encontrarle un origen a la función cognoscitiva, porque el origen debería hallarse antes que esta misma relación, lo que no puede acontecer porque ella es desde el comienzo, integramente, una inmediatidad.

Todavía queda, sin embargo, una posibilidad. El origen del conocimiento 2 puede identificarse con el fundamento del mismo? Nihil est sine rationie. Sin duda, el conocimierto puede ser fundamentado y, en la descripción de su problemática, es posible aludir a un principinm grande. Pero toda fundamentación del conocimiento alude necesariamente a principios que se encuentran allende esa nuda y simple relación entre sujeto y objeto que es la instancia esencial irreductible del proceso fundamentado. La fundamentación del pruceso cognoscitivo hunde necesariamente sus raíces en la concepción general del ser real, del ser ideal y también del ser espiritual. Históricamente el origen del conocimiento se ha encontrado siemprẹ, así, en el extrarradio de la relación cognoscitiva como tal.

La conclusión đe nuestro análisis es que el problema 
del origen del conocimiento envuelve un principio irracional y constituye por lo tanto una aporia. Si el origen es un factor funcional que se halla incrustado en el ser o en el proceso originado; si el origen es un factor intuente o inmanente en el ser $a$ en el proceso que deriva de él; y si la relación cognoscitiva es una relación para si, que se of rece como tha integridad conclusa, insurgente en su plenitud metafisica de manera inmediata, al mismo tiempo primera y última ¿cómo serát posible descubrir racionalmente el "origen" del conocimiento?.

\section{Excurso.}

El origen del conocimiento no es inmanente a la razón y cae en el mundo que Nicolai Hartmann designa con el nombre de transinteligible. Sin embargo, la idea de orige: como tal es racional y resulta privada de esta cualidad cuanclo se le aplica al problema concreto que tratamos ahora cle esclarecer. ¿Cuál es el motivo?

La relación cognoscitiva es una realiclad de naturaleza metafísica. Ahora biencen nuestro concepto, no cabe aplicar el concepto de origen a lo metafísico. El origen participa de la esencia de las realidades naturales. Su ser es un ser en cl tiempo. Lo ideal en cambio no es en el tiempo: st esencia es extratemporal. Sin duda. lo icleal requiere de lo real para actualizarse. La relación cognoscitiva está necesitada de la realiclad del objeto y también de la realidad del ser espiritual para devenir actual. Fero el conocimiento no puede identificarse con ninguno de los seres reales-temporales que lo actualizan. El ser icleal, las relaciones icleales, pueden ser fundamentadas. Pero ellas constituyen estructuras encerradas en sí mismas, en sus propias determinaciones intemporales. 
No puede cncontrarse su "origen" como tampoco es dable clescubrir su "causa".

Unicamente el ser natural puede ser originado. Cabe sin ducla cuestionar el origen de la naturaleza, del universo. Es posible referirse también al origen de nuestras representaciones, sentimientos, voliciones, etc. En las esferas de lo real natural, todo es el resultado de un proceso que tiene un punto de partida en un origen o en una causa.

El motivo por el cual la idea de origen aparece como irracional aplicada al problema del conocimiento, es que tal aplicación comporta una metábasis, la traslación del origen a un reino del ser que no se acuerda con su realidad empírica y temporal. En verdad, no hay un factor que origine el conocimiento. Tocla explicación del origen de nuestro conocimiento aparece a su vez originada por la proyección al mundo de lo idcal de una categoría que está dada solamente en el mundo natural. Todo planteamiento del problema del origen del conocimiento envuelve un falsamiento tanto del concepto cle origen como de la naturaleza metafísica de la relación cognoscitiva.

En esta irracionalidad del problema del origen del conocimiento debemos distinguir finalmente la razón por la cual la cuestión ha revestido significaciones tan diversas en la Historia de la Filosofía y su planteamiento no ha sido formulado con claridad suficiente.

El problema del origen del conocimiento en los sistemas racionalistas.

La tesis fundamental del racionalismo gnoseológico afirma que el verdadero conocimiento es únicamente el conocimiento válido. El conocimiento se expresa en el juicio. Son 
juicios que enuncian conocinientos válidos aquellos que ostentan las notas de universalidad y necesidad. Necesidad y universalidad no pueden encontrar su fuente en la experiencia. Han de derivar, por to tanto, del sujeto y, en éste, de la razónt.

También pueden formularse juicios con el material que nos of rece la experiencia sensible. Pero en este caso la predicación of rece algo que, en la reverberación iridiscente de lo transitorio y lo mutable, se destaca nada más que como un conjunto de determinaciones históricas (Wolff) y precarials. Esa estructura de determinaciones se oírece hic et nunc, con las restricciones que en los órdenes universales del espacio y del tiempo tiene lo fugaz y evanescente. Luego, el ser así de esas determinaciones no es un ser necesariamente así.

Las determinaciones que la razón desenvuelve con exclusión de la experiencia, presentan por el contrario los epígrafes esenciales del verdadero conocimiento. La predicáción sobre el ente irradia entonces en su plenitud y se resiste a toda disminución de carácter espacial o temporal. El conocimiento racional ês asíla instanchácereada de un régimen concluído. Nada hay que puedic menoscabar su fuerza necesaria, nada que pueda limitar sus proyecciones universales.

Son los sistemas racionalistas aquellos en los cuales con mayor nitidez puede distinguirse el error de aplicar el concepto de origen a la relación cognoscitiva. La necesidad y la universalidad son notas lógicas. Son notas que se insertan no en la relación en que el objeto es aprehendido por el sujeto sino en el reino de lo objetivo en si mismo considerado. La necesidad y la universaliđad no están dadas " $\mathrm{Cn}$ " la razón ni son funciones racionales. Son, por el contrario, notas dadas inmediatamente "en" el ser ideal que sirve de objeto al conocimiento. La necesidad y la universalidad son datos que se 
of recen rcaliter en el objeto mismo del conocimiento. El hombre no es el legislador de la naturaleza. La necesidad y la universalidad no son engenđradas por la razón ni tienen en clla su fuente. Dichas notas, como inmanentes a la estructura del ser ideal, permanecen indiferentes al hecho de que sean o no aprehendidas por el pensamiento racional. El sujeto llega a ellas por el raciocinio, sin duda; es decir, simplemente las descubre en el ser ideal, las aprehende como determinaciones que se actualizan en dicha aprehensión, pero que están dadas intemporalmente en aquél. Ahora bien. Estas determinaciones ideales tampoco pueden originar el conocimiento; $\mathrm{I}^{\circ}$ porque ellas son trascendentes al pensamiento racional; $2^{\circ}$ porque ellas son indiferentes a toda consciencia cognoscente; y $3^{\circ}$ porque son, justamente ideales.

El racionalismo gnoseológico comete el error de hacer inmanente al proceso del conocimiento aquello que por esencia le es trascendente. En dos sentidos se cumple esta inmanentización. En primer lugar, porque se identifica el objeto de la predicación con el juicio predicativo mismo. Sin duda, el pensamiento ideāb puede formular juicios universales y necesarios. Pero el objeto iđeal como tal es solamente uno de los polos de la relación cognoscitiva; el objeto permanece siempre allende el sujeto, le es irrevocablemente trascendente, de ninguna manera se incorpora en la consciencia ni desde luego en los enunciados judicativos que el sujeto sienta sobre él. El triángulo puede ser objeto de juicios universales y necesarios. Pero el triángulo como tal, como objeto ideal, posee una realidad trascendente al sujeto y a su función racional. Razón y objeto no son idénticos. Juicio y objeto del juicio no son idénticos. No pueđe identificarse el triángulo, como realidad autónoma y trascendente al suje- 
to, con la razón que descubre sus propiedades. El tienc una realidad irreductible. La prueba ontológica de la existencia de Dios no es válida porque el objeto del conocimiento tiene una realidad trascendente a la predicación racional.

En segundo lugar, la tesis racionalista incluye dentio de la relación cognoscitiva, algo que es trascendente a esta relación, a saber, la razón misma (lo que por lo demás ya está implicado en el párrafo anterior). La razón es una función del ser espiritual y está, como tal, más acá de la relación cognoscitiva. También la razón es trascendente al conocimiento como relación entre el sujeto $y$ objeto, aunque esta trascendencia tiene por decirlo asi signo inverso a aquella que ostenta el objeto. En tanto que el objeto está más allá, la razón está más acá de la relación cognoscitiva.

Históricamente, la philosophia rationalis ha buscado el origen del conocimiento, la fuente de la universalidad y de la necesidad, fuera del conocimiento mismo. Son fuentes del conocimiento, por ejemplo, las ideas platónicas, el nus cósmico. Las cosas empíricas participan del mundo superior de las ideas. El almáne con ocasión "de la experiencia, tiene la reminiscencia de un orden ideal, trascendente por lo tanto al objeto mismo del conocimiento. El nus cósmico alimenta por radiación nuestra alma, la ilumina continuamente desde una esfera trascendente al objeto del conocimiento y a la conciencia cognoscente. $\mathrm{Y}$ así, en todos los sistemas racionalistas se puede distinguir siempre un elemento extraño y trascendente a la función misma del conocimiento.

Una observación final. Puede ser referido a un origen aquello que, de una u otra manera, deviene. La universalidad y la necesidad no son notas que devienen en el objeto 
del conocimiento. Este, en cuanto tal es una quididad o esencialidad que muestra inmediatamente en su estructura las notas en cuestión. Ellas no devienen. Simplemente, están allí.

Carlos Cueto Fernandint.



